\title{
Perspectives on Inclusion: Students with LD, their Parents, and their Teachers
}

\author{
Linda Chmiliar \\ Athabasca University
}

\begin{abstract}
One of the most significant changes in education over the last few decades is the movement toward inclusive education. Many schools have adopted an inclusive approach of educating students with learning disabilities (LD) in the regular classroom. The present study utilized a multiple case study approach to examine the perspectives of stakeholders in inclusive education. Each case consisted of a student with LD, a parent of the student, and the inclusive education classroom teacher. A number of similarities and differences in perspectives among the student, parent, and teacher in each case were identified. Similarities and differences in perspectives were also found among each of the case studies. Several practical implications arose from the research.
\end{abstract}

One of the most significant changes in education over the last decade is the movement toward inclusive education. Although students with special learning needs are being taught in regular classrooms, there is little documented empirical evidence of the effects of full inclusion on students with learning disabilities (LD; Vaughn \& Schumm, 1995). A number of studies have indicated that students with LD do not fare well academically and make minimal progress in the general education classroom (Fuchs, Fuchs, Fernstrom, 1993; Klingner, Vaughn, Hughes, Schumm, \& Elbaum, 1998). There is also research indicating that students with LD can achieve in the inclusive classroom (Manset \& Semmel, 1997; Waldron \& McLeskey, 1998). Unfortunately, the question of whether inclusive programs are effective for students with LD is inconclusive. Inclusive classrooms are diverse, dynamic settings with myriad relationships between students, teachers, and parents. Therefore, it is important to look at how stakeholders experience the diverse aspects of inclusion (Schumm \& Vaughn, 1998) and examine their perspectives to develop a comprehensive picture of the inclusive classroom. 


\section{Literature Review}

There is a body of research on the consequences of educating children with disabilities in inclusive classrooms that focus on students', parents', teachers', and multiple stakeholders' perspectives on inclusion placements.

Teacher perspectives. Classroom teachers' views regarding inclusion have been discussed at length in the literature. Scruggs and Mastropieri (1996) found that overall, teachers expressed positive attitudes toward the inclusion of students with disabilities and saw benefits and value to inclusion; however, special educators may be more supportive of full inclusion than general educators (Elhoweris \& Alsheikh, 2004). Teachers expressed less favourable attitudes toward teaching students with severe disabilities (Cook, 2001); however, these attitudes can change as a result of experience and/or training (Martin, Johnson, Ireland, \& Claxton, 2003).

In the studies reviewed, teachers frequently reported that they did not have sufficient time or training (Bunch, Lupart, \& Brown, 1997; Macmillan \& Meyer, 2006; Scruggs \& Mastropieri, 1996) to teach in inclusive classrooms. The lack of training may result in low confidence (King \& Edmunds, 2001) and feelings of guilt (Macmillan \& Meyer, 2006). Teachers also reported a lack of appropriate resources and support (Macmillan \& Meyer, 2006; Prochnow, Kearney, \& Carroll-Lind, 2000), had issues with workload (Macmillan \& Meyer, 2006), and expressed the need for administrative support (Bunch et al., 1997). Teachers working in inclusive collaborative environments reported positive attitudes and outcomes (DeSimone \& Parmar, 2006; Malone, Gallagher, \& Long, 2001). Teacher beliefs regarding instructional characteristics, which contribute to the success of inclusion, such as groupings, teaming, and collaborative practices, have also been reported (McLeskey \& Waldron, 2002).

Parent perspectives. There are few studies that have examined the perspectives of parents of students with LD. Many parents report positive support for inclusive classroom placement (Myles \& Simpson, 1990) due to reported increases in self-esteem, opportunities for socialization, increases in student enjoyment and participation (Gibb et al., 1997), and positive social and emotional outcomes (Leyser \& Kirk, 2004). Parent reluctance for reintegration has also been reported (Green \& Shinn, 1994). Nugent (2007) found that parents expressed a preference for inclusive settings, but when involved in the setting were actually more satisfied with segregated services. Parents have expressed a constant need to be involved with the school, positive and negative experiences with the school, and social concerns (Waggoner \& Wilgosh, 1990). Leyser and Kirk (2004) noted parents' concerns regarding social isolation, negative attitudes, quality of instruction, and teacher training and skills in inclusive classrooms.

Student perspectives. Students with disabilities have strong individual perceptions about their school placement (Shah, 2007). They liked the inclusive classroom because it was better for making friends (Vaughn \& Klingner, 1998); reported a preference for working in small groups and doing harder work in inclusive classrooms (Klingner, Vaughn, Schumm, Cohen, \& Forgan, 1998); and were more accepted, had higher self perceptions, and more satisfying relationships (Wiener \& Tardif, 2004). On the other hand, students with LD liked attending the resource room because they "got extra help" and engaged in "fun" activities; however, they were concerned about activities missed in the regular education classroom (Padeliadu \& Zigmond, 1996). Students may prefer to receive specialized instruction outside of the regular classroom 
(Vaughn \& Klingner, 1998) because they can concentrate better and get help readily (Vaughn et al., 1998).

Numerous studies in the literature have reported on the value of perceptions of students with LD regarding their academic experiences. Students have identified programs and courses that were too difficult or uninteresting for them and expressed an interest in socialization (Kortering \& Braziel, 2002). Students have also discussed the helpfulness of selected interventions and accommodations in high school algebra (Kortering, deBettencourt, \& Braziel, 2005) and the effects of middle school to high school experiences on self perceptions (Letrello \& Miles, 2003).

Multiple perspectives. Several studies have examined and compared the perceptions of social skills by teachers and students. McLeod, Kolb, and Lister (1994) found that regular education teachers' perceptions differed significantly from students with LD regarding the social and school skills important for success. Similarly, Pavri and Monda-Amaya (2001) found that teachers and students identified different roles for themselves, and the teacher and student social intervention strategy preferences differed. Pudlas (2003) examined the different perceptions of students with special education needs and teachers in inclusive classrooms and found that students with special needs had lower self concept scores and secondary teachers expressed more negativity regarding inclusion. Meltzer, Katzir, Miller, Reddy, and Roditi (2004) looked at student perceptions of their academic difficulties and changes in these perceptions after strategy instruction, as well as changes in teachers' perceptions of student strategy use: Students were more consistent in their use of strategies after instruction and teachers perceived the students as being more strategic.

Very few studies, however, have examined and compared teacher and parent perceptions of inclusion. Seery, Davis, and Johnson (2000) examined teacher and parent perceptions and found differences in the opinions of both groups regarding the future of inclusion, although both groups supported inclusion and its continuation. In addition, Goupil, Tasse, Garcin, and Dore (2002) found differences in parent and teacher perceptions of individualized transition planning.

Parent, teacher, and student perspectives were examined in a number of studies. Frederickson, Dunsmuir, Lang, and Monsen (2004) found that parents, students, and teachers all reported academic and social advantages to mainstream settings. Agreement among the stakeholders regarding the need for students to possess some level of self-determination, the need for communication, and the need for administrative support were identified (Lehmann, Bassett, \& Sands, 1999). Wilczenski et al. (1997) found differences in the meaning of inclusion among members of the different stakeholder groups. Ritter, Michel, and Irby (1999) examined differences in the perceptions of middle school students, their parents, and teachers regarding student confidence. After a move to an inclusive program, parents and teachers reported that the students displayed increased self confidence and self esteem, camaraderie, and higher expectations.

After examining the few studies that have investigated multiple stakeholder perspectives, a number of gaps have become apparent. First, very few studies have systematically examined and compared the inclusion experiences of students with LD, their parents, and their regular education teachers: The majority of the studies reported separate perspectives of each of the stakeholder groups with no cross comparisons. Examining and comparing perspectives is important for gaining a more comprehensive understanding of inclusion experiences and potential differences among experiences, as well as identifying factors that may contribute to, or provide barriers to, successful experiences. Inclusive classrooms are inherently complex environments that involve the interactive participation of all key stakeholders to be successful. 


\section{Present Study}

The purpose of this study was to explore how students with LD, their teachers, and their parents experience inclusion. The research took place in a suburban school district that was in close proximity to the researcher. The school district identified five possible students for this study who met the criteria of having LD, who were enrolled in an inclusive classroom in Grade 5 or 6 , and where the teacher and parent were interested in participating in the study. Once the school district identified the students, the researcher obtained consent from each parent and teacher. Five case studies were conducted that consisted of a transcribed interview with a student with LD, the student's inclusive education teacher, and a parent of that student (see Appendices A, B, C, for interview guides).

A number of strategies were used to organize and analyze the data. First, the researcher used self-reflection to eliminate personal involvement with the subject material. The second step involved reduction of the data: The data were examined carefully, defined, and analyzed. Key phrases and statements related to the phenomenon were identified and their meanings were interpreted. These meanings were examined and statements regarding each participant's perspective were developed. These statements were summarized and an initial summary of each case study was reviewed with the participants; feedback obtained was incorporated into the data.

The data analysis occurred within the framework of a case study analysis (Stake, 1995). As the purpose of case study analysis is to gather comprehensive, systematic, and in-depth information about each case of interest, each case analysis included all the interview data and field notes for the impressions gathered during the interview process (Patton, 1990). The data were organized into a comprehensive description that included all of the major information that was used in the case analysis and case study. The data were edited, parts fitted together, and organized topically. Each individual case study analysis begins with a description of each student, teacher, and parent perspective. Finally, the case studies were integrated across cases, exploring common threads and differences between and across the students, teachers, and parents.

\section{Results}

\section{Case Study 1}

Student. David is 11 years old and is included in a regular Grade 6 classroom. He indicated that he likes Grade 6 because he has a lot of friends and his teacher is nice to him. He reported that if he is having trouble he is able to talk to his teacher who makes his "life easier." The only thing that David does not like is being teased about his weight. David said that he finds Grade 6 challenging, but he is doing okay because he has "been taking homework home... and not leaving everything until the last minute." David reported that completing homework assignments independently is very challenging and difficult. He also said that working with a partner is helpful because "a partner can help me when I really need it." He talked positively about how the teacher provides him with easier reading materials, additional help on tests, copies of notes, reduced number of questions, and modified homework assignments.

Teacher. David's teacher, Mr. T., has been teaching for 29 years. This year he has 29 students and 6 of them have disabilities. Mr. T. expressed commitment to inclusion, and although he receives support from a student support team he feels uncomfortable when children included 
in the classroom have severe problems. He indicated that David is successful in class and has many friendships in the classroom. He felt that David also has a "fragile ego" that interferes with his learning. Mr. T. reported that he adapts classroom instruction by providing readers, additional time for homework and tests, adapted marking, and help from an assistant. He said that he takes a personal interest in the progress of his students: "I do a lot...with these children, and particularly kids like (David). I coach them through things." During the interview, Mr. T. indicated that he has regular contact with the parents and that meetings to discuss David's Individual Education/Program Plan (IEP/IPP) are held with David's parents.

Parent. David's parents reported that David really struggled in the first few years of school and as a result David was "very negative and very upset." David progressed in the learning assistance classroom, but did not like going there because he felt he was in the "dumb room." The transition to the regular classroom was very difficult for David and it resulted in him "crying all night." David's parents reported that they write or type David's homework for him because he has difficulty completing all of his homework at night. They also reported that Grade 6 is "David's best year so far" because he likes the teacher and appears to be getting long well. David's parents indicated that in their opinion, many of the difficulties at school are due to a lack of communication between teachers from year to year. They expressed mixed feelings about adaptations for David in the classroom and that the adaptations "do not make a lot of difference." David's parents indicated that they have regular contact with the school, but could not remember the goals or objectives on the IPP or if there was an IPP meeting this year. They expressed uncertainty as to how to be involved in the IPP process.

\section{Case Study 2}

Student. Brian is 11 years old and is included in a regular Grade 5 classroom. Brian attends the learning assistance classroom for reading instruction for part of each morning. He indicated that the two best things this year are his friends and his teacher. He reported that he does not like the assistant that works with him and he engages in inappropriate behaviours in order to be removed from the situation. He also did not like being teased at school as it is "really frustrating." Brian indicated that this year is harder than previous years, but he is able to "focus better" and has made progress in academics. He reported that he experiences frustration completing classroom assignments: "It's hard just to get stuff done," and homework is very hard. He said that when he tries to work at home "it just gets crazy." Brian reported that the teacher helps him by explaining things, but indicated that working with a partner could be a challenge "depending on who you're working with." He indicated that "sometimes I want help on some things...but if it is something that will affect me in life I want to learn to do it myself." Brian spoke negatively about marking adaptations saying that he "wants an honest grade that I did all by myself without any help from anyone." He reported that he likes the learning assistance classroom because he gets "more help" and the activities are "fun." However, he would like to progress academically so that he would no longer have to attend the learning assistance room: He said, "if I'm totally behind and having too many troubles, then I'll go back because I need it.”

Teacher. Brian's teacher, Mrs. S., has been teaching for 30 years. This year she has 24 students in her class; 9 students have an identified disability. The students with LD attend the learning assistance classroom for Language Arts, and there is a student support team in the 
school. Mrs. S. felt that "inclusion, for many children, is very beneficial for everybody. However, if children cannot get involved with any of the activities...I think inclusion is hopeless." Mrs. S. reported that Brian "has a lot of social problems getting along with others, following the rules of the class" and that group work is "a problem for Brian." Mrs. S. reported that she has not had success with testing modifications as Brian refuses to have anyone read the test for him and "he would rather work things out for himself." Mrs. S. also indicated that homework is a daily struggle with Brian. She has had limited contact with Brian's parents because his mother and the learning assistance teacher work together.

Parent. Brian's mother indicated that school has always been a struggle for Brian and after Grade 1 she attempted to home school him. Brian returned to school for Grade 3 and participated in the learning assistance program which was "absolutely critical" to his survival. Brian's mother reported that they still rely heavily on the learning assistance teacher. She was concerned about the teasing of students in learning assistance, but was not sure if the teasing continues to bother Brian. She felt that "this year has probably been the hardest and the most productive" and she was aware that he chooses to complete classroom tasks independently. Brian's mother has minimal involvement in the IPP because she "trusts" the learning assistance teacher with whom she is in consistent contact.

\section{Case Study 3}

Student. Jim is 12 years old and is included in a regular Grade 6 classroom. He reported that the best thing about this year is that he gets to stay in one classroom and does not have to leave to go to the learning assistance classroom because "it is more easy to keep track of things that way." Jim also liked having friends in the classroom and reported that having teacher help is very important. Jim reported that learning assistance was good for learning to "do better and harder" work and for "concentrating." He found it very difficult to move out of the learning assistance classroom to the regular classroom as it is "kind of a very hard change to go into a regular system...you're kind of more not sure about what you have to do." Grade 6 has "been a pretty good year." Jim reported that homework is a concern as "it kind of makes me really frustrated." He indicated that his teacher reduces the number of questions on assignments and working with a partner "kind of works faster."

Teacher. Jim's teacher, Mr. M., has been teaching for 22 years. This year he has 28 students in the classroom; 9 students have an identified disability. Mr. M. participates in a student support team in the school. He expressed a positive perspective of inclusion: "they are gaining more by being in the classroom than they are at being totally segregated" and that Jim "has a couple of friends... and he seems very happy." Mr. M. indicated that he reduces the amount of work Jim must complete on assignments "usually by half" and adapts his expectations in terms of the "quality of the work." Homework expectations are also reduced and there are testing modifications. Mr. M. reported that he has regular contact will all of the parents and meets with the parents regarding the IPP during the scheduled parent teacher interview times.

Parent. Jim's father reported that Jim started exhibiting learning problems at a very young age and was sent to the learning assistance classroom in grades 1 through 4 for help. The learning assistance greatly helped Jim and he handled the transitions in and out of the learning 
assistance program quite well. Jim's father said, "I think that (Jim) has only one relatively close friend at school, but he relates very well to adults." He felt that "this year...is better than last year" largely because he is consistently working with Jim. He was very concerned with the amount of homework assigned and copies the questions down for Jim to help him get his homework done. He reported that he does not believe that Jim is on an IPP this year.

\section{Case Study 4}

Student. Alex is 11 years old and is included in a regular Grade 5 classroom. He attends the learning assistance classroom every morning for Language Arts. Alex stated that one of the things he likes best about this year is his friends. He also told the interviewer that this year is better than other years because he has a "better teacher" who makes learning "fun." Alex reported positive experiences in the learning assistance classroom as it helps him "concentrate" and he learns strategies such as how to study. Alex talked about his recent move out of the learning assistance classroom into the regular classroom for Math. He indicated that he was very frustrated and distressed because he was not able to keep up with the assignments. Alex said working in pairs helps him learn and he can ask his teacher for help. He also indicated that his teacher gives him copies of notes and less homework.

Teacher. Alex's teacher, Mr. B., has been teaching for 13 years. There are 27 students in the classroom; 8 students have disabilities. He reported that he collaborates with the learning assistance teacher to solve learning problems in the classroom. He also reported that inclusion causes difficulties for teachers, but that "teachers have to try to find extra time for those kids who have those learning disabilities." Mr. B. talked about Alex's recent move from the learning assistance classroom for Math to the regular classroom: "(Alex) was a little upset after even, I think, the first or second day," but has adjusted. Mr. B. said that he makes a number of adaptations in his classroom including providing extra time, readers for tests, reduced number of questions, reduced homework, and partner and group work. He reported that the IPP is developed by the regular classroom teacher and the learning assistance teacher as a team, and then is discussed with the parents.

Parent. Alex's mother reported that Alex experienced learning difficulties in grades 1 and 2, but no additional support was provided to him. In Grade 3, Alex attended the learning assistance classroom and has since made "quite a leap of improvement." She indicated that Alex has good social skills and "seems to get along well with kids." She also reported that Grade 5 has been much better than previous years because Alex is "now accomplishing" things. She reported that Alex likes Math now that "he's more challenged." Alex tells her that he enjoys the learning assistance classroom, but worries about what he is missing in the regular classroom: "There are some frustrations when he comes back to the classroom." Alex's mother indicated that she spends considerable time working with him on homework. She reported that being a parent of a child with LD is a "huge" responsibility. "If I'm not a hundred percent involved in that homework activity, he will get a zero tomorrow." Unlike the other parents, Alex's mother was aware of the goals on his IPP and stated that she talks with the teachers early in the school year. 


\section{Case Study 5}

Student. Jason is 12 years old and is included in a regular Grade 6 classroom. He reported that he likes his teacher this year because "she helps me" and he is doing "pretty well." Last year in Grade 5, "Nobody was helping me. I was getting tons of homework...I could never finish it." This year he indicated that he is able to get his homework done and feels "good" about that. Jason reported that his teacher reduces the number of questions he has to complete and receives copies of notes, but he does not always enjoy working with a partner on assignments. At the end of the interview Jason was very quiet and looked at the floor. He whispered to the interviewer, "Sometimes I cry...I can't control it." He mentioned that he cries in class because of "work and stuff or some friends." He said "lots of things" make him very frustrated.

Teacher. Jason's teacher, Mrs. W., has been teaching for 20 years. This year there are 27 students in her class and 8 of them have a disability. There is a learning assistance teacher in the school for support. Mrs. W. felt that "we should offer both (inclusion and learning assistance)" to students depending on their needs. She reported that she reduces the quantity of work and homework, and implements partner and group activities. However, Mrs. W. reported that Jason "does not take kindly to help," and does not like working with a partner because "he likes to be autonomous and do it on his own." Mrs. W. reported that she has regular contact with his parents and meets with them regularly to review the IPP.

Parent. Jason's mother reported that Jason experienced a great deal of difficulty learning in the early grades; he hated school and repeated Grade 1. In Grade 2 Jason participated in a reading intervention program and his reading improved dramatically. In grades 4 and 5 he had a teacher who did not understand him and felt "that he was lazy." Fortunately, he participated in the learning assistance classroom which helped him acquire needed skills and provided needed support. She said, "He has some friends. Not really close friends. Occasionally one will come over, and rarely will he be invited over to somebody's house-which bothers him." Jason's mother reported that Grade 6 has been "one of the best years he's ever had in school" because he has a teacher who understands him and gives him the help he needs. Homework has been a major source of frustration for Jason and his mother: "It was torture in our house for homework." She reported consistent contact with the regular education teacher, but if there is a problem, she still contacts the learning assistance teacher for help. She could not remember any of Jason's IPP goals.

\section{Analysis and Discussion}

\section{Comparisons Among Students}

All 5 students were boys with LD attending Grade 5 and 6 classrooms in a suburban school district. The 3 Grade 6 boys-David, Jim, and Jason-are fully included in the regular classroom, but attended the learning assistance classroom in previous years. The 2 Grade 5 boys, Brian and Alex, still receive additional instruction for Language Arts in the learning assistance classroom, but spend the majority of their time in the regular classroom (see Table 1).

All 5 of the students commented that one of the things they liked best was having friends in the regular classroom. This finding is consistent with previous research (e.g., Klingner, 
Table 1

Student Information

\begin{tabular}{cccc}
\hline Case & Student & Grade & Classroom \\
\hline 1 & David & 6 & fully included \\
2 & Brian & 5 & learning assistance for LA \\
3 & Jim & 6 & fully included \\
4 & Alex & 5 & learning assistance for LA \\
5 & Jason & 6 & fully included \\
\hline
\end{tabular}

Vaughn, Schumm, Cohen, \& Forgan, 1998; Vaughn \& Klingner 1998). Four of the five students reported that the best thing this year was their teacher; they talked about how their teacher helped and supported them in class, and described positive feedback they received. In all of these cases, one of the most important aspects of the inclusive classroom in the students' perception was the teacher. Freeman, Stoch, Chan, and Hutchinson (2004) found similar results in a retrospective study of adults with learning difficulties who found that strong teacher-student relationships was a significant factor in high school completion. Perhaps the relationship that the student develops with the teacher, and how this relationship is perceived by the student, is an important area that should be considered in the inclusive classroom.

All of the students reported that this year was the best year compared to previous years and that they were doing "better this year." This may be related to the fact that students generally indicate a preference for the setting that they are currently in (Jenkins \& Heinen, 1989). However, this finding may also be because the students' needs were currently being met with classroom adaptations as well as the positive relationships they had with their teachers and peers.

The students in this study reported that they liked attending the learning assistance classroom because they engaged in "fun" activities and received additional help, which is consistent with the literature (e.g., Jenkins \& Heinen, 1989; Klingner, Vaughn, Schumm et al., 1998; Padeliadu \& Zigmond, 1996). One student reported missing activities when attending the learning assistance class. This result was also found by Padeliadu and Zigmond (1996). Similar to findings by Guterman (1995), two of the students receiving support in the learning assistance classroom experienced teasing as a result of attending that classroom. Despite the difficulties, all the students indicated that although they learned to concentrate, learned strategies, and learned skills in the learning assistance classroom, their preference was to be in the inclusive classroom.

The students in this study described a number of classroom adaptations that they preferred. They indicated a preference for reduced questions on assignments and exams, and four students required assistance in copying notes from the board-preferences consistent with the literature (e.g., Fulk \& Smith, 1995; Vaughn, Schumm, Niarhos, \& Daugherty, 1993). Also consistent with the literature, students in this study expressed differing perspectives regarding adapted assignments, grading adaptations, and group or partner work. Some students with LD preferred that no adaptations be made (Vaughn et al., 1993), while others reported mixed preferences to work with partners (Vaughn, Schumm, Klingner, \& Saumell, 1995) and receive grading adaptations (Bursuck, Munk, \& Olson, 1999). These findings indicate a need to match classroom adaptations to the strengths, weaknesses, and preferences of individual students rather than taking a "one size fits all" approach. 
The student perspectives in this study regarding homework are similar to those expressed in the literature. The students found homework to be a slow, difficult, and frustrating process (Nelson, Epstein, Bursuck, Jayanthi, \& Sawyer, 1998) and reported satisfaction with, or a need to have, the opportunity to complete homework at school where they can access help and support from the teachers. Homework is a source of concern for students with LD and policies in inclusive classrooms need to be examined.

Finally, 3 of the 5 students in this study expressed frustration with teasing or bullying in the school. This finding is consistent with the literature (e.g., Cooney, Jahoda, Gumley, \& Knott, 2006; Norwich \& Kelly, 2004) where the majority of the students reported experiencing negative stigmatizing situations and bullying. Teasing is a serious source of concern and there is a need for schools to promote the social and emotional well-being of students with learning difficulties (Cooney et al., 2006).

\section{Comparisons Among Teachers}

This study revealed that a number of teacher perspectives regarding the inclusion of students with disabilities into the classroom were similar to perspectives expressed in the literature. The teachers in this study reported positive perspectives regarding inclusion (Bunch et al., 1997; Villa, Thousand, Meyers, \& Nevin, 1996). Two of the teachers reported a reluctance to teach students with severe disabilities and all the teachers indicated that a lack of time is a major concern (Scruggs \& Mastropieri, 1996). Three of the teachers also indicated that they believed that school should provide the inclusive experience as well as remedial support.

Unlike the previous research that identified concerns as to whether or not effective strategies are implemented in inclusive classrooms (Whinnery, King, Evans, \& Gable, 1995), the teachers in this study reported extensive use of classroom adaptations in testing, marking, assignments, instructional groupings, homework, note-taking support, and motivational support. The teachers also discussed how they apply each of these classroom adaptations dependent on the individual needs of each student with LD, identifying why certain strategies are successful or unsuccessful for the particular student. However, none of the teachers reported teaching learning strategies in the classroom, nor did they report providing any remedial support to the students. This finding is consistent with the literature (e.g., Baker \& Zigmond, 1990; Zigmond \& Baker, 1997), where teachers reported making "routine" adaptations, such as variations in materials, grouping arrangement, and goals, but did not report making "specialized" instructional adaptations and failed to provide needed specializations. It is important that general education teachers teaching students with LD in their classrooms do more than just reduce the classroom requirements. It is necessary to provide instruction in learning strategies and provide some remedial support for learning difficulties.

All of the teachers in this study had many years of experience including children with special needs in their classrooms, in settings with collaborative support. All but one teacher spoke strongly about the importance of having the opportunity and time to collaborate with colleagues to problem solve and plan as a team. This finding is consistent with reports by Austin (2002); Minke, Bear, Deemer, and Griffin (1996); Soodak, Podell, and Lehman (1998); and Villa et al. (1996). Collaboration in inclusive settings can enrich the teaching experience, help the teacher plan programs for students with special needs, and assist with challenges in the classroom. 


\section{Comparisons Among Parents}

Analysis of the parents' responses provides insight into several areas. The parents in this study described in detail the difficulties their child experienced in the early grades, expressed negative attitudes toward school personnel, and described difficulties accessing support for their child. Soodak and Erwin (2000) also reported that parents' early adverse experiences resulted in negative perspectives. In addition, Stoddard and Valcante (2001) reported that it is not uncommon to hear parents indicate that the classroom teacher said, "He'll grow out of it," then find later that their child had a disability and could have benefited from intervention if the disability had been identified. These comments highlight the importance of having a process in place in kindergarten and Grade 1 to identify children who are experiencing difficulties in school and provide appropriate supports for these children, rather than waiting for a pattern of failure to be established before providing support.

All of the parents reported that they currently have or have had regular goals, were not sure they had attended an IPP meeting, expressed uncertainty as to the purpose of the IPP, or were not convinced that their child had an IPP. This finding is of considerable concern and has been reported previously in the literature (e.g., Gibb et al., 1997; Green \& Shinn, 1994). It appears that more effort is needed to inform parents about the IPP and include them in the IPP process. If parents are included in the process as partners, then perhaps the progress reported on goals and objectives will be more memorable and relevant to them.

Parents in this study reported the overwhelming challenges of dealing with homework and the time commitment and responsibility involved in keeping up with homework and dealing with school issues. Duhaney and Salend (2000) and Waggoner and Wilgosh (1990) reported similar results.

All of the parents in this study reported that the current school placement in the inclusive classroom had been the best ever, even though in some cases it had also been the most difficult year. This may be due to their child's increased self-esteem, expanded social relationships and interactions, increased willingness to participate in group activities, and in some cases improved grades and attitudes in an inclusive program (Gibb et al., 1997). This may also be due to the students' reported relationships with the current teacher or because the current classrooms have many adaptations in place that are helping the students participate in ways they have not been able to in the past.

\section{Comparisons Among Case Studies}

A number of similarities and differences in perspectives were common among the case studies. There were differing perspectives between the teachers and the parents regarding the content and process of the IPP in the majority of the case studies. This finding suggests that although the teachers perceive that they are doing an adequate job working with the parents and reporting on the IPP, this perception is not shared by the parents. As mentioned previously, this suggests that there may be a need for schools to look at how they are currently including parents in the IPP process.

There were also differences in stakeholder perspectives in three of the case studies regarding the level of frustration reported by the students and the level of frustration or absence of information about frustration reported by the parents and the teacher. In more than one case the student expressed considerable frustration with educational decisions made by the teachers and 
parents, sometimes to the detriment of the student's self-esteem. Research studies discussing differences in student, teacher, and parent perceptions have been noted elsewhere (i.e., Lehmann et al., 1999; Pavri \& Monda-Amaya, 2001). These results underline the importance of exploring student perceptions regarding their school experiences and in including students in the decisionmaking process.

In comparing stakeholder perspectives in the present study, similarities were found regarding how the student was progressing during the school year and the social standing and friendships of the student. Ritter et al. (1999) also noted similarities in the perspectives of students, parents, and teachers regarding students' social abilities. In contrast, other studies (e.g., McLeod et al., 1994; Pavri \& Monda-Amaya, 2001) found differences in the perceptions of students, parents, and teachers regarding the social standing and friendships of students with LD.

\section{Implications for Practice}

The results of this study suggest several practical implications for schools. The parents in this study want to be partners in the process of inclusive education and commit time and energy to ensuring their child's success in school. Unfortunately, the information flow tends to be primarily from the school system to the parents. Based on the experiences of these parents, it is important for schools to provide parents with information regarding their role in the IPP process as well as encouragement and opportunities to become active partners. It is also important that parents and teachers have an opportunity to share common perspectives to more effectively determine a child's needs.

It is evident from the present research that students with LD can provide invaluable information regarding their "lived" experience in the inclusive classroom. Adaptations or experiences perceived by students to be negative can have a negative impact on them and in the classroom. Conversely, knowledge about adaptations that students perceive to be helpful can help the teacher build a positive and successful learning environment and contribute to program development and evaluation, allowing students to take an active part in the education process (Shah, 2007).

The teachers in this study identified the need for adequate planning time and access to collaboration with their peers. Unfortunately, current funding issues in schools make it very difficult for school administration to provide the time and professional support necessary for successful collaboration. It is necessary to find new and innovative ways to build collaboration in schools. This requires concerted effort by leadership personnel to create and foster an environment where collaboration is not only possible, but also supported.

\section{Limitations}

Although the present research provided insights into the perspectives of students, parents, and teachers of the inclusive classroom, the conclusions of this research should be interpreted with several cautions. First, all of the participants were located in a single suburban school district limiting the generalizability of the results. Second, all of the classrooms and teachers had been recommended for participation in the study by the school administration. It is possible that the researcher was referred to teachers who demonstrated positive attitudes and practices towards inclusion. Third, all the students in the study were identified by the teachers as being good can- 
didates for the study. Although there may be some bias in the selection of the research participants, all participants freely discussed issues and perspectives during the interview process. Fourth, interview data may have been subject to recall error, reactivity of the interviewee to the interviewer, and self-serving responses (Patton, 1990). However, an interview guide was utilized to ensure the same general categories of information were discussed with each participant.

\section{Future Research}

The results of this study raise several areas for future research. Further research could explore gender differences in perspectives, the perspectives of other participants in the inclusive classroom, and differences between elementary and junior/senior high school levels. Research is also needed to explore ways in which students' perceptions can be better incorporated into decision making and program planning and how their perceptions might improve services in regular classroom settings.

\section{Conclusion}

The results of this research illustrate that each stakeholder in the inclusive classroom experiences inclusion in a different way and has a different perspective. Important similarities and differences in the perspectives exist. Consideration of the stakeholder perspectives in the inclusive classroom may assist in the identification of barriers to inclusion, provide information on strategies in the inclusive classroom that are and are not effective, and provide a basis for discussion on how perceptions might be used to improve services in the inclusive classroom setting.

\section{References}

Austin, V. (2002). Teachers' beliefs about co-teaching. Remedial and Special Education, 22, 245-255.

Baker, J., \& Zigmond, N. (1990). Are regular education classes equipped to accommodate students with learning disabilities? Exceptional Children, 56, 515-526.

Bunch, G., Lupart, J., \& Brown, M. (1997). Resistance and acceptance: Educator attitudes toward inclusion of students with disabilities. Toronto, ON: York University, Faculty of Education.

Bursuck, W., Munk, D., \& Olson, M. (1999). The fairness of report card grading adaptations: What do students with and without learning disabilities think? Remedial and Special Education, 20, 84-92.

Cook, B. (2001). A comparison of teachers' attitudes toward their included students with mild and severe disabilities. Journal of Special Education, 34, 203-214.

Cooney, G., Jahoda, A., Gumley, A., \& Knott, F. (2006). Young people with intellectual disabilities attending mainstream and segregated schooling: Perceived stigma, social comparison and future aspirations. Journal of Intellectual Disability Research, 50, 432-444.

DeSimone, J., \& Parmar, R. (2006). Middle school Mathematics teachers' beliefs about inclusion of students with learning disabilities. Learning Disabilities Research \& Practice, 21, 98-110.

Duhaney, L. M., \& Salend, S. (2000). Parental perceptions of inclusive educational placements. Remedial and Special Education, 2, 121-128.

Elhoweris, H., \& Alsheikh, N. (2004, November). Teachers' attitudes toward inclusion. Paper presented at the New York State Federation of the Council for Exceptional Children, Albany, NY. 
Frederickson, N., Dunsmuir, S., Lang, J., \& Monsen, J. (2004). Mainstream-special school inclusion partnerships: Pupil, parents and teacher perspectives. International Journal of Inclusive Education, 8, 37-57.

Freeman, J., Stoch, S., Chan, J., \& Hutchinson, N. (2004). Academic resilience: A retrospective study of adults with learning difficulties. Alberta Journal of Educational Research, 50, 5-21.

Fuchs, D., Fuchs, L., \& Fernstrom, P. (1993). A conservative approach to special education reform: Mainstreaming through trans-environmental programming and curriculum-based measurement. American Educational Research Journal, 30, 149-177.

Fulk, C., \& Smith, P. (1995). Students' perceptions of teachers' instructional and management adaptations for students with learning or behavior problems. The Elementary School Journal, 95, 409418.

Gibb, G., Young, J., Allred, K., Dyches, T., Egan, M., \& Ingram, C. (1997). A team based junior high inclusion program: Parents perceptions and feedback. Remedial and Special Education, 18, 243249.

Goupil, G., Tasse, M., Garcin, N., \& Dore, C. (2002). Parent and teacher perceptions of individualized transition planning. British Journal of Special Education, 29, 127-135.

Green, S. K., \& Shinn, M. R. (1994). Parents attitudes about special education and reintegration: What is the role of student outcomes? Exceptional Children, 61, 269-281.

Guterman, B. (1995). The validity of categorical learning disabilities services: The consumer's view. Exceptional Children, 62, 111-124.

Jenkins, J., \& Heinen, A. (1989). Students' preferences for service delivery: Pull-out, in-class, or integrated models. Exceptional Children, 55, 516-523.

King, W., \& Edmunds, A. (2001). Teachers' perceived needs to become more effective inclusion practitioners: A single school study. Exceptionality Education Canada, 11(1), 3-23.

Klingner, J., Vaughn, S., Hughes, M., Schumm, J., \& Elbaum, B. (1998). Academic outcomes for students with and without learning disabilities in inclusive classrooms. Learning Disabilities Research and Practice, 13, 153-160.

Klingner, J., Vaughn, S., Schumm, J., Cohen, P., \& Forgan, J. (1998). Inclusion or pull-out: Which do students prefer? Journal of Learning Disabilities, 31, 148-158.

Kortering, L., \& Braziel, P. (2002). A look at high school programs as perceived by youth with learning disabilities. Learning Disability Quarterly, 25, 177-199.

Kortering, L., deBettencourt, L., \& Braziel, P. (2005). Improving performance in high school Algebra: What students with learning disabilities are saying. Learning Disability Quarterly, 28, 191203.

Lehmann, J., Bassett, D., \& Sands, D. (1999). Students' participation in transition related actions: A qualitative study. Remedial and Special Education, 20, 160-169.

Letrello, T., \& Miles, D. (2003). The transition from middle school to high school: Students with and without learning disabilities share their perceptions. Clearing House, 76, 212-214.

Leyser, Y., \& Kirk, R. (2004). Evaluating inclusion: An examination of parent views and factors influencing their perspectives. International Journal of Disability, Development \& Education, 5, 271285.

Macmillan, R., \& Meyer, M. (2006). Inclusion and guilt: The emotional fallout for teachers. Exceptionality Education Canada, 16(1), 25-43.

Malone, M., Gallagher, P., \& Long, S. (2001). General education teachers' attitudes and perceptions of teamwork supporting children with developmental concerns. Early Education and Development, $12,577-592$.

Manset, G., \& Semmel, M. (1997). Are inclusive programs for students with mild disabilities effective? A comparative review of model programs. The Journal of Special Education, 31, 155-180.

Martin, B., Johnson, J., Ireland, H., \& Claxton, K. (2003). Perceptions of teachers on inclusion in four rural Midwest school districts. Rural Educator, 24(3), 3-10. 
McLeod, T., Kolb, T., \& Lister, M. (1994). Social skills, school skills, and success in the high school: A comparison of teachers' and students' perceptions. Learning Disabilities Research \& Practice, 9, 142-147.

McLeskey, J., \& Waldron, N. (2002). Inclusion and school change: Teacher perceptions regarding curricular and instructional adaptations. Teacher Education and Special Education, 25, 41-54.

Meltzer, L., Katzir, T., Miller, L., Reddy, R., \& Roditi, B. (2004). Academic self-perceptions, effort, and strategy use in students with learning disabilities: Changes over time. Learning Disabilities Research and Practice, 29, 99-108.

Minke, K., Bear, G., Deemer, S., \& Griffin, S. (1996). Teachers' experiences with inclusive classrooms: Implications for special education reform. The Journal of Special Education, 30, 152-180.

Myles, B., \& Simpson, R. (1990). Mainstreaming modification preferences of parents of elementary-age children with learning disabilities. Journal of Learning Disabilities, 23, 234-239.

Nelson, J., Epstein, M., Bursuck, W., Jayanthi, M., \& Sawyer, V. (1998). The preferences of middle school students for homework adaptations made by general education teachers. Learning Disabilities Research \& Practice, 13, 109-117.

Norwich, B., \& Kelly, N. (2004). Pupils' views on inclusion: Moderate learning difficulties and bullying in mainstream and special schools. British Educational Research Journal, 30, 43-65.

Nugent, M. (2007). Comparing inclusive and segregated settings for children with Dyslexia-Parental perspectives from Ireland. Support for Learning, 22, 52-59.

Padeliadu, S., \& Zigmond, H. (1996). Perspectives of students with learning disabilities about special education placement. Learning Disabilities Research \& Practice, 11, 15-23.

Patton, M. (1990). Qualitative evaluation and research methods (2nd ed.). Newbury Park, CA: Sage Publications.

Pavri, S., \& Monda-Amaya, L. (2001). Social support in inclusive schools: Student and teacher perspectives. Exceptional Children, 67, 391-411.

Prochnow, J., Kearney, A., \& Carroll-Lind, J. (2000). Successful inclusion: What do teachers say they need? New Zealand Journal of Education Studies, 35(2), 157-177.

Pudlas, K. (2003). Inclusive education practice and perceptions of students and teachers. Exceptionality Education Canada, 13(1), 49-64.

Ritter, C., Michel, C., \& Irby, B. (1999). Concerning inclusion: Perceptions of middle school students, their parents, and teachers. Rural Special Education Quarterly, 18(2), 10-16.

Schumm, J., \& Vaughn, S. (1998). Getting ready for inclusion: Is the stage set? Learning Disabilities Research and Practice, 10, 169-179.

Scruggs, T., \& Mastropieri, M. (1996). Teacher perceptions of mainstreaming/inclusion, 1958-1995: A research synthesis. Exceptional Children, 63, 59-74.

Seery, M. E., Davis, P., \& Johnson, L. J. (2000). Seeing eye-to-eye: Are parents and professionals in agreement about the benefits of preschool inclusion? Remedial and Special Education, 21, 268$278,319$.

Shah, S. (2007). Special or mainstream? The view of disabled students. Research Papers in Education, $22,425-442$.

Soodak, L., \& Erwin, E. (2000).Valued member or tolerated participant: Parents' experiences in inclusive childhood settings. Journal of the Association for Persons with Severe Handicaps, 25(1), 29-41.

Soodak, L., Podell, D., \& Lehman, L. (1998). Teacher, students and school attributes as predictors of teachers' responses to inclusion. Journal of Special Education, 31, 480-497.

Stake, R. (1995). The art of case study. Thousand Oaks, CA: Sage Publications.

Stoddard, K., \& Valcante, G. (2001). Families of children in elementary age services. In D. O'Shea, L. O'Shea, R. Algozzine, \& D. Hammitte (Eds.), Families and teachers of individuals with disabilities: Collaborative orientations and responsive practices (pp. 155-178). Toronto, ON: Allyn and Bacon.

Vaughn, S., \& Klingner, J. (1998). Students' perceptions of inclusion and resource room settings. The Journal of Special Education, 32, 79-88. 
Vaughn, S., \& Schumm, J. (1995). Responsible inclusion for students with learning disabilities. Journal of Learning Disabilities, 28, 264-270; 290.

Vaughn S., Schumm, J., Klingner, J., \& Saumell, L. (1995). Students' views of instructional practices: Implications for inclusion. Learning Disability Quarterly, 18, 236-248.

Vaughn, S., Schumm, J., Niarhos, F., \& Daugherty, T. (1993). What do students think when teachers make adaptations? Teaching and Teacher Education, 9,107-188.

Villa, R., Thousand, J., Meyers, H., \& Nevin, A. (1996). Teacher and administrator perceptions of heterogeneous education. Exceptional Children, 63, 29-45.

Waggoner, K., \& Wilgosh, L. (1990). Concerns of families of children with learning disabilities. Journal of Learning Disabilities, 23, 97-98, 133.

Waldron, N., \& McLeskey, J. (1998). The effects of an inclusive school program on students with mild and severe learning disabilities. Exceptional Children, 64, 395-405.

Whinnery, K., King, M., Evans, W., \& Gable, R. (1995). Perceptions of students with learning disabilities, inclusion versus pull-out services. Preventing School Failure, 40(1), 5-9.

Wiener, J., \& Tardif, C. (2004). Social and emotional functioning of children with learning disabilities: Does special education placement make a difference? Learning Disabilities Research and Practice, 19, 20-32.

Wilczenski, F., Barry-Schneider, E., Reddington, R., Blais, W., Carreira, K., \& Daniello, A. (1997). Using stakeholder interviews to evaluate inclusive education. Providence, RI (Eric Document Reproduction Service No. ED 412697).

Zigmond, J., \& Baker, J. (1997). A comprehensive examination of an experiment in full inclusion. In T. Scruggs \& M. Mastropieri (Eds.), Advances in learning and behavior disabilities (Vol. 2, pp. 101-134). Greenwich, CT: JAI Press.

\section{Authors' Note}

Correspondence concerning this article should be addressed to Linda Chmiliar, Assistant Professor, Psychology, Athabasca University, Athabasca, AB. Email: lindac@athabascau.ca 


\section{Appendix A \\ Interview Guide: Student}

Background Information

Age

Grade

Number of students in the class

\section{Interview Guide}

Tell me what you like in your class this year. What don't you like? What, if anything, is different about your class this year compared to other years?

How are you doing in school this year? What do you do well in? What do you have difficulties with?

What helps the kids in the classroom learn better? What helps you learn better?

If you are having difficulties with your classroom lesson and need extra help, how do you get help? How does your teacher or others help you?

What kinds of help work best for you?

Is there anything else you would like to tell me about your classroom or about school this year?

\section{Appendix B \\ Interview Guide: Teacher}

\section{Background Information}

Years of teaching experience

Years of teaching students with disabilities

Number of students in the class

Number of students with disabilities in the class

How students with disabilities are assigned to the class

Courses taken on students with disabilities

Services that are provided to the student in/out of the classroom

Philosophy of inclusion

Nature of the student's difficulties

\section{Interview Guide}

Tell me about any instructional modifications or teaching arrangements you make in class.

What impact do different adapted educational approaches have on instruction?

How does the student with learning disabilities fare in the classroom, and on the playground?

What would help the student with learning disabilities to be more successful? Why?

Tell me about your involvement with the parents of the student with learning disabilities.

\section{Appendix C Interview Guide: Parent}

\section{Background Information}

Age of child

Grade

Nature of the learning difficulties

\section{Interview Guide}

Tell me about your child's educational program this year. How is the program affecting your child?

What, if any, concerns do you have?

What does your child say about school this year?

Tell me about any involvement you have had with the school. What, if any, changes would you make?

How does this year compare to other years? What makes if better or worse?

Tell me about any IPP goals that may have been set for your child this year. Do you think they are being achieved?

Why or why not? 